\title{
II. Beitrag zur Bestimmung des Pupillenabstandes
}

Rud.

\author{
Helmbold
}

Augenarzt in Danzig

AB und $C B$ sind zwei senkrecht zueinander stehende Spiegel. Fällt ein Strahl G D auf den Spiegel A B, so wird der Strahl nach E und von dort parallel mit D G nach H reflektiert.

$* 3 / 4 \mathrm{a}=\wedge \$=\wedge_{\mid}$.s. $\quad * 4 \gamma \mathrm{r}=, 3 / 8 \delta$

$-3 / 8 \beta+-3 / 8 \gamma=1 \mathrm{E}$

$4 \tau=\mathrm{iR}-* 3 / 8 \beta$

$4 \chi+2 \mathrm{R}-24 \beta=2 \mathrm{R} 4 \mathrm{x}=24 \mathrm{P}$ oder $=-=3 / 4 \alpha+<=3 / 4 \varepsilon$ Daher G D parallel H E.

Jeder Strahl, welcher in einer zu den Spiegeln A B und B C se $\pi$ krechten Ebene auf A B fällt, wird vom Spiegel B C so reflektiert, dass er mit dem ersteren parallel läuft und umgekehrt.

Voraussetzung bleibt, dass der einfallende Strahl mit dem zuerst reflektierenden Spiegel einen

Winkel bildet, der kleíner als $90^{\circ}$ ist.

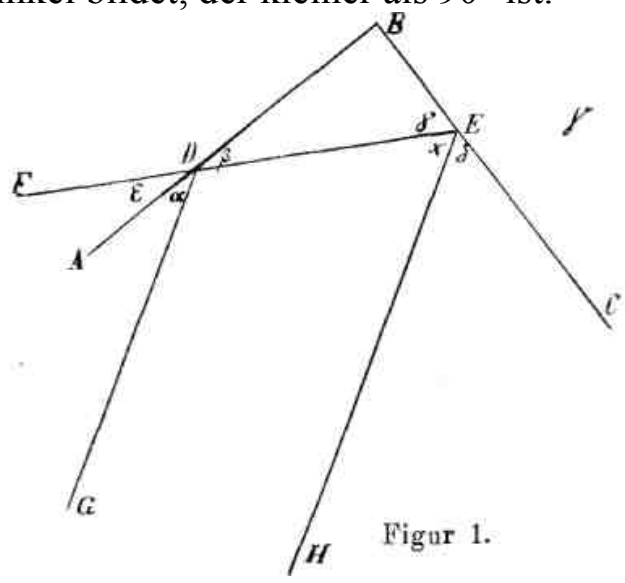

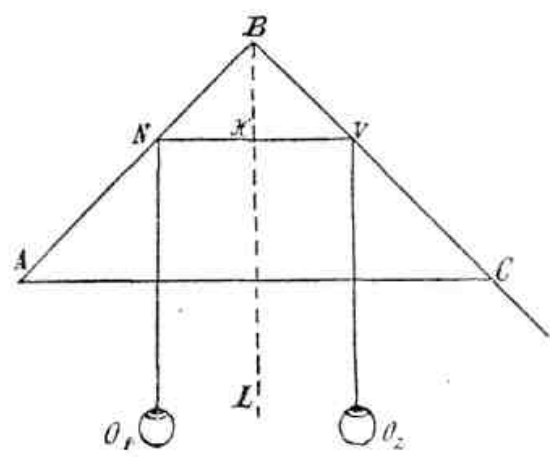

Figur 2.

Die Spiegel A B und B C werden durch einen Querstab A C so verbunden, dass Abstand AB $\approx B C$ ist. An dem Querstab befinden sich kleine verstellbare Polster, die zum Anlegen des unteren Orbitalrandes an das Instrument dienen und den Abstand der Orbitalränder vom Querstab regulieren. In der den Spiegel-

46 Helmbold, Beitrag zur Bestimmung des Pupillenabstandes.

winkel AB C halbierenden Ebene BL bewegt sich durch Schraubengewinde ein dünner Stab parallel zur Schnittlinie der Spiegel A B und B C. Bringt man nun den Apparat so vor sein Gesicht, dass rechtes und linkes Auge gleichweit von dem Querstab A C entfernt sind und den gleichen Abstand von dem jeseitigen Spiegel (A B und B C) haben und blickt man gerade aus, dann wird, wie aus der obenstehenden rechten Figur 


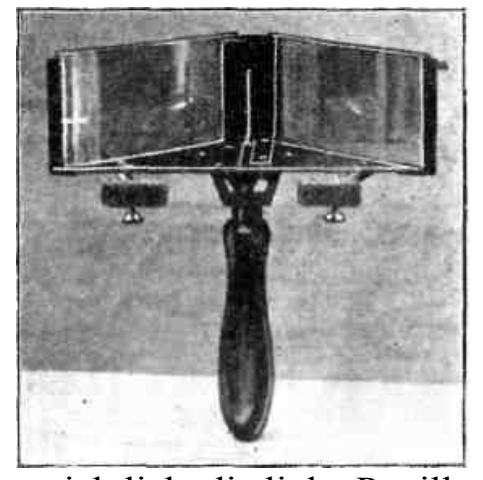

ersichtlich, die linke Pupille sich auf der Netzhaut des rechten Auges und die rechte Pupille auf der Netzhaut des linken Auges abbilden. Yerschiebt man den in B L beweglichen Stab X langsam, so kommt er allmählich in eine solche Lage, dass er beiderseits die Pupillen zu halbieren scheint. Die doppelte Entí'ernung von $\mathrm{X}$ nach $\mathrm{B}$ gibt dann genau den Abstand der Pupillen von einander an. Yon Pupille Ox (linkes Auge) gelangen die Strahlen nach $\mathrm{N}$ $1 / 8 \mathrm{AN} \mathrm{Ot} \approx 45^{\circ}$ ), werden nach $\mathrm{Y}$ und von da nach 02 (rechtes Auge $\left.\left[-3 / 8 \mathrm{C} \mathrm{V02}=4 \delta^{\circ}\right]\right)$ reflektiert und umgekehrt. Da N X B und $\mathrm{YXB}$ gleichschenkelige Dreiecke sind, so ist $\mathrm{NX}=\mathrm{BX}=\mathrm{YX}$ oder $\mathrm{NX}+\mathrm{XV} \approx 2 \mathrm{BX}$.

(Der Apparat ist von Gebrüder Penner-Danzig gebaut.) 